\title{
Post-antibiotic effects and post-antibiotic sub-minimal inhibitory concentration effects of chlorhexidine against oral bacteria
}

\author{
Min Seok Yoo ${ }^{1,2}$ and Si Young Lee $\mathrm{L}^{3,4 *}$
}

${ }^{1}$ Master's Student, Department of Microbiology and Immunology, College of Dentistry, Gangneung-Wonju National University, Gangneung, Republic of Korea ${ }^{2}$ Master's Student, Research Institute of Oral Science, Gangneung-Wonju National University, Gangneung, Republic of Korea

${ }^{3}$ Professor, Department of Microbiology and Immunology, College of Dentistry, Gangneung-Wonju National University, Gangneung, Republic of Korea

${ }^{4}$ Professor, Research Institute of Oral Science, Gangneung-Wonju National University, Gangneung, Republic of Korea

Post-antibiotic effect (PAE) is defined as the suppression of bacterial growth for a particular duration after brief exposure to an antimicrobial agent. Chlorhexidine is a widely used biocide found in antiseptic products; however, its PAE remains unclear. In this study, PAE, post-antibiotic sub-minimum inhibitory concentration (MIC) effects (PA-SME), and sub-MIC effects (SME) of chlorhexidine on oral bacteria were investigated. For PAE measurement, bacteria were exposed to 10x MIC chlorhexidine for $1 \mathrm{~min}$, which was then eliminated by washing. For determining PA-SME, bacteria were exposed to $0.1,0.2$, and $0.3 \times$ MIC chlorhexidine during the post-antibiotic phase and to sub-MIC chlorhexidine for the measurement of SME. PAE, PA-SME, and SME of chlorhexidine were observed. The PAE lasted for $0.9 \mathrm{hr}$ for Streptococcus mutans, $0.1 \mathrm{hr}$ for Streptococcus gordonii, and $0.35 \mathrm{hr}$ for Lactobacillus acidophilus. The PA-SME against oral bacteria lasted for a longer duration with increasing chlorhexidine concentrations. The PA-SME against oral bacteria lasted for a substantially longer period than SME did. The present study illustrates the existence of chlorhexidineinduced PAE, PA-SME, and SME against oral bacteria, thereby extending the pharmacodynamic advantages of chlorhexidine.

Key Words: Chlorhexidine, Oral bacteria, Post-antibiotic effect

@C This is an open-access article distributed under the terms of the Creative Commons Attribution Non-Commercial License (http://creativecommons.org/licenses/by-nc/4.0) which permits unrestricted noncommercial use, distribution, and reproduction in any medium, provided the original work is properly cited.

\section{INTRODUCTION}

Post-antibiotic effect (PAE) refers to the suppression of bacterial growth following limited periods of exposure to an antibiotic and removal of the antimicrobial agent [1,2]. The PAE may last for several hr, depending on the concentration of antibiotic and the susceptibility of the target organisms [1,2]. PAE has been well documented for many microorganisms, and cited as an explanation for the suc- cess of intermittent dosing regimens [3,4]. When intermittent dosing is applied in clinical practice, there is a gradual decrease in the antibiotic concentration, wherein an initial supra-inhibitory concentration will be followed by a period using doses that are below the minimum inhibitory concentration (MIC). It has been shown that there are postantibiotic sub-MIC effects (PA-SME) in bacteria that were previously exposed to supra-inhibitory antibiotic concentrations. Furthermore, these effects are unique from the

Received January 29, 2020; Revised February 11, 2020; Accepted February 13, 2020

*Corresponding author: Si Young Lee, Department of Microbiology and Immunology, Research Institute of Oral Science, College of Dentistry, Gangneung-Wonju National University, 7 Jukheon-gil, Gangneung 25457, Republic of Korea.

Tel: +82-33-640-2455, Fax: +82-33-642-6410, E-mail: siyoung@gwnu.ac.kr

Copyright $\odot$ 2020, Oral Biology Research Institute 
sub-MIC effects (SME) observed in bacteria that were not exposed to supra-inhibitory antibiotics $[5,6]$. Importantly, the PAE and PA-SME are inherent properties of most antimicrobial agents, and are associated with the duration of the effect.

Chlorhexidine is a widely used biocide in antiseptic products, including hand and oral products, and as a disinfectant and preservative [7]. Chlorhexidine is a cationic biguanide microbicide with a broad spectrum of activity against bacteria and fungi. It is used widely in both clinical and domestic situations [8]. Early work showed that chlorhexidine induces a rapid and irreversible loss of bacterial cytoplasmic components, including pentoses, even at low concentrations [9]. However, there was no obvious relationship between leakage and the number of organisms killed. Furthermore, despite its microbicidal effect, chlorhexidine has several adverse effects, including poor taste, tooth discoloration, and desquamation and soreness of the oral mucosa [10].

The present study sought to evaluate the PAE, PA-SME, and SME of chlorhexidine against oral bacteria, which would help extending the pharmacodynamic advantages of chlorhexidine.

\section{MATERIALS AND METHODS}

\section{Microorganisms and growth conditions}

Streptococcus gordonii DL1 which is initial colonizer and bacterial species related to the dental caries such as Streptococcus mutans ATCC 25175 and Lactobacillus acidophilus ATCC 4355 were used in this experiment. Oral Streptococci were grown in brain heart infusion broth (BHI; Becton; Dickinson and Company, Sparks, MD, USA) for $18 \mathrm{hr}$ at $37^{\circ} \mathrm{C}$ in aerobic conditions supplemented with $5 \% \mathrm{CO}_{2}$. Lactobacillus were grown in Lactobacillus MRS medium (Becton) for 18 hr at $37^{\circ} \mathrm{C}$ in aerobic conditions supplemented with $5 \%$ $\mathrm{CO}_{2}$.

\section{Chemicals and determination of the minimum inhibitory concentration}

A stock solution of chlorhexidine digluconate (Sigma
Chemical Co., St. Louis, MO, USA) was prepared in BHI broth or MRS broth $(2.12 \mathrm{mg} / \mathrm{mL})$. MIC was determined by two-fold serial macro-dilution of chlorhexidine digluconate in BHI or MRS, with an inoculum of approximately $10^{5}$ cells $/ \mathrm{mL}$. A range of concentrations were tested $(0.003$ $\mu \mathrm{g} / \mathrm{mL}$ to $2.12 \mathrm{mg} / \mathrm{mL}$ ). The MIC was defined as the lowest concentration of chlorhexidine digluconate that inhibited the growth of bacteria.

\section{Post-antibiotic incubation and post-antibiotic effect determination}

The PAE was measured using a previously described method $[5,6]$. Bacteria in the exponential growth phase were obtained by culturing for $18 \mathrm{hr}$, and were diluted with $\mathrm{BHI}$ broth to obtain a starting inoculum of $10^{9} \mathrm{CFU} /$ $\mathrm{mL}$. The strains were exposed to $10 \times$ MIC of chlorhexidine for $1 \mathrm{~min}$ at $37^{\circ} \mathrm{C}$. The unexposed control strains were incubated in BHI broth without chlorhexidine. The bacteria were washed three times with phosphate-buffered saline (pH 7.2) to eliminate chlorhexidine, and were diluted into fresh BHI broth by centrifugation. The residual chlorhexidine concentration after the three washes was assumed to be lower than $10^{-5} \times$ MIC by calculation, and therefore likely insignificant. The unexposed control strains also underwent three washes. To determine the PAE, cultures with bacteria in the post-antibiotic phase and the unexposed controls were incubated at $37^{\circ} \mathrm{C}$ for an additional $11 \mathrm{hr}$. The bacterial growth was determined by measuring the optical density of the bacterial culture at $660 \mathrm{~nm}$ every hr over the $11 \mathrm{hr}$ time course.

The PAE was defined according to the following formula: $\mathrm{PAE}=\mathrm{T}-\mathrm{C}$, where $\mathrm{T}$ is the time required for the chlorhexidine-treated cultures to reach $50 \%$ of the maximum absorbance and $\mathrm{C}$ is the corresponding time for the unexposed control.

\section{Determination of PA-SME and SME}

To determine PA-SME, 0.1, 0.2 or $0.3 \times$ MIC of chlorhexidine was added to cultures in the post-antibiotic phase, which were prepared as described above. The tubes were incubated at $37^{\circ} \mathrm{C}$ for $1 \mathrm{~min}$. The bacterial growth was de- 
termined by measuring the optical density of the bacterial culture at $660 \mathrm{~nm}$, as described above. PA-SME was also measured in control cultures that were not exposed to $10 \times$ MIC of chlorhexidine or the sub-MIC chlorhexidine dose. The PA-SME was defined according to the following formula: $\mathrm{PA}-\mathrm{SME}=\mathrm{T}_{\mathrm{PA}}-\mathrm{C}$, where $\mathrm{T}_{\mathrm{PA}}$ is the time required for the cultures previously exposed to the $10 \times$ MIC of chlorhexidine followed by sub-MIC chlorhexidine to reach $50 \%$ of the maximum absorbance, and $\mathrm{C}$ is the corresponding time for the control.

The SME was measured using control cultures that were not exposed to $10 \times$ MIC chlorhexidine, but were exposed to $0.1,0.2$ or $0.3 \times$ MIC. The SME was defined as: $\mathrm{SME}=\mathrm{T}_{\mathrm{S}}{ }^{-}$ $\mathrm{C}$, where $\mathrm{T}_{\mathrm{S}}$ is the time required for the cultures exposed only to the sub-MICs to reach $50 \%$ of the maximum absorbance, and $\mathrm{C}$ is as defined above.

\section{RESULTS}

The MIC of chlorhexidine was $4.1 \mu \mathrm{g} / \mathrm{mL}$ in $S$. mutans, $16.6 \mu \mathrm{g} / \mathrm{mL}$ in $S$. gordonii, and $33.1 \mu \mathrm{g} / \mathrm{mL}$ in L. acidophilus (Table 1). The average PAE, PA-SME, and SME values from two experiments are shown in Table 2. The PAE against S. mutans lasted for a mean duration of $0.90 \mathrm{hr}$, whereas the mean duration was $1.90 \mathrm{hr}(0.1 \times \mathrm{MIC}), 2.70 \mathrm{hr}(0.2 \times$ MIC), and $3.45 \mathrm{hr}(0.3 \times \mathrm{MIC})$ for PA-SME. Furthermore, SME lasted for a mean duration of $0.75 \mathrm{hr}(0.1 \times \mathrm{MIC}), 1.50$ $\mathrm{hr}(0.2 \times \mathrm{MIC})$, and $1.85 \mathrm{hr}(0.3 \times \mathrm{MIC})$. Additionally, PAE lasted for a mean duration of $0.10 \mathrm{hr}$ in $S$. gordonii and 0.35 $\mathrm{hr}$ in L. acidophilus. Interestingly, the PAE against $S$. gordonii and L. acidophilus lasted for shorter durations than PAE against $S$. mutans.

The time for which PA-SME lasted for oral bacteria increased as the concentration of chlorhexidine increased. Furthermore, the time for which PA-SME lasted for oral bacteria was substantially longer than that for which SME

Table 1. Minimal inhibitory concentration determined by macro dilution method

\begin{tabular}{lc}
\hline \multicolumn{1}{c}{ Bacteria } & Chlorhexidine $(\mu \mathrm{g} / \mathrm{mL})$ \\
\hline Streptococcus mutans ATCC 25175 & 4.1 \\
Streptococcus gordonii DL1 & 16.6 \\
Lactobacillus acidophilus ATCC 4355 & 33.1 \\
\hline
\end{tabular}

lasted. Fig. 1 shows the average PAE, PA-SME, and SME of two experiments using oral bacteria.

\section{DISCUSSION}

Pharmacodynamic parameters, such as PAE and PA-SME, have become increasingly important to understand antimicrobial activity and determine the optimal dosing schedule for antibiotics $[1,3,11,12]$. Even though it is known that several antibiotics can induce PAE, PA-SME, and SME in diverse bacteria [1,2], studies using oral Streptococci remain limited. Furthermore, the PAE, PA-SME, and SME of chlorhexidine in oral bacteria remain unclear.

Lee [13] reported that amoxicillin induced PAE, PA-SME, and SME in both Streptococcus sanguinis and S. gordonii, although the effect duration was shorter in $S$. sanguinis. In the present study, the PAE, PA-SME, and SME of chlorhexidine were evaluated using three oral bacterial strains. Lee [13] reported that, for $S$. gordonii, PAE of amoxicillin lasted for a mean duration of $2.0 \mathrm{hr}$. In the present study, PAE of chlorhexidine against $S$. gordonii lasted for a mean duration of $0.1 \mathrm{hr}$. Thus, PAE of chlorhexidine was shorter than that of amoxicillin against $S$. gordonii. We propose that PAE, PA-SME, and SME of chlorhexidine against oral bacteria may differ from those of amoxicillin, and that there may be variations in the durations of these effects for different antimicrobial agents. Many studies have reported that

Table 2. PAE, PA-SME, and SME of chlorhexidine with oral bacteria

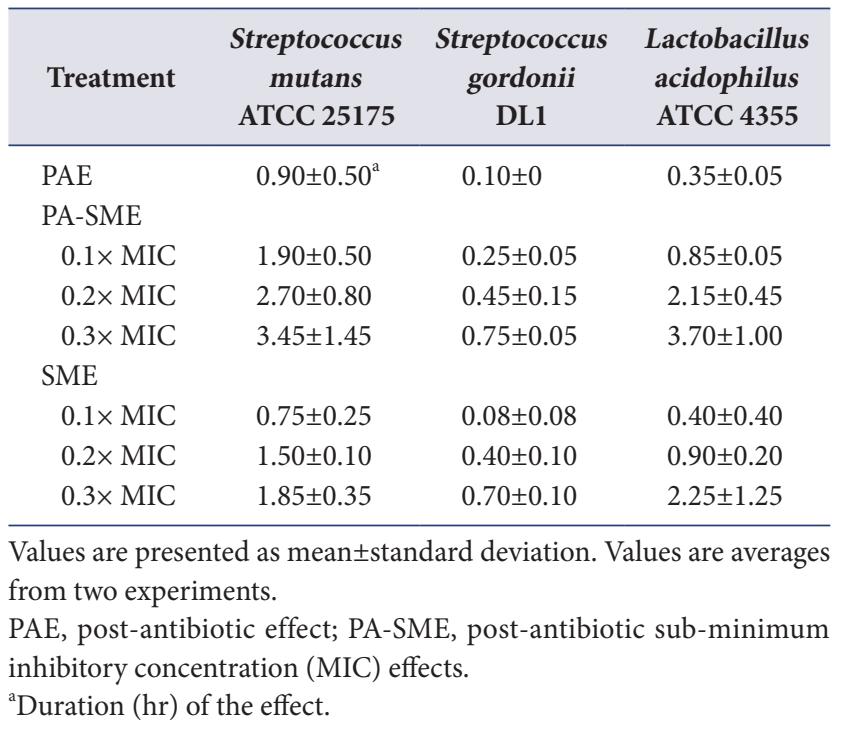



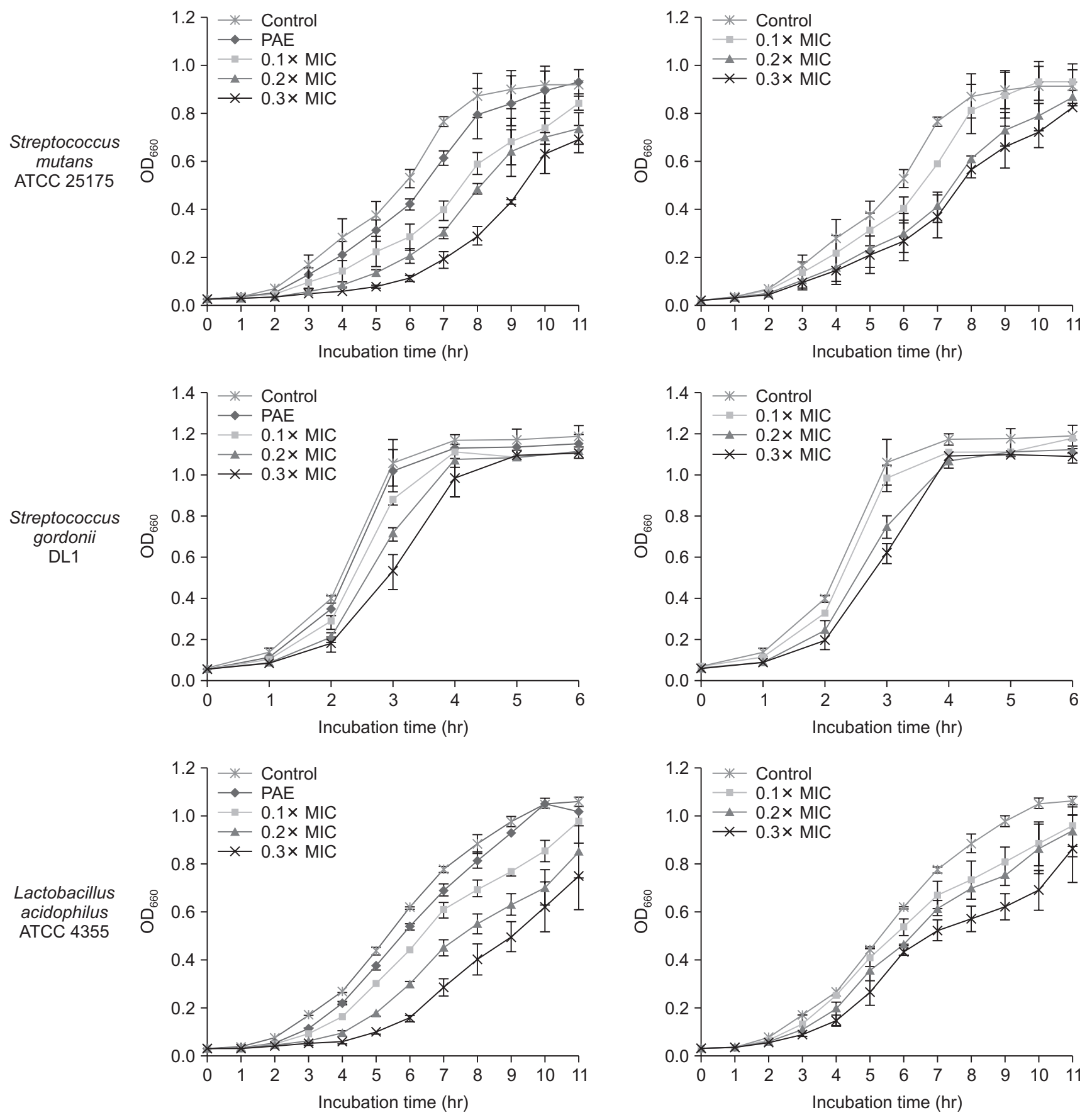

Fig. 1. Post-antibiotic effect (PAE) and post-antibiotic sub-minimum inhibitory concentration (MIC) effects (PA-SMEs) (A), and SMEs (B) of chlorhexidine in oral bacteria. The PAE was induced by $10 \times$ MIC chlorhexidine for $1 \mathrm{~min}$, and chlorhexidine was eliminated by washing. The PA-SMEs were studied by the addition of $0.1,0.2$ and $0.3 \times$ MIC during the post-antibiotic phase, and the SMEs were studied by exposure of the bacteria to chlorhexidine at the sub-MICs only. Values indicate means of two experiments and the error bars indicate standard deviations of the mean. $\mathrm{OD}_{660}$, optical density at $660 \mathrm{~nm}$. 
different combinations of bacteria and antibiotics show different PAEs [1]. It is also possible that the drug concentration, the growth phase of the bacteria, the duration of antibiotic exposure, and the method of drug removal could be responsible for these differences. Li et al. [14] suggested that the major determinants of PAE were cellular recovery from nonlethal damage following antibiotic exposure, the times required for the dissociation of the antibiotics from the receptors, production of growth inhibitory substances in bacteria, and the effect on the DNA synthesis. The present study illustrates the existence of chlorhexidine-induced PAE, PA-SME, and SME against $S$. mutans, S. gordonii, and L. acidophillus, thereby reinforcing the pharmacodynamic advantages of chlorhexidine when targeting these bacteria.

In most antibiotic-bacterium combinations, the drug concentration will fall below the MIC during the dosing interval. Additionally, a supra-inhibitory concentration of a drug will always be followed by sub-MICs in vivo. Growth suppression periods during the post-antibiotic-phase may occur because it is impossible to eliminate all of the drug at once in vivo. Although the PAE and PA-SME of chlorhexidine were observed in this study, the in vivo effects remain unclear. Although PAE is a well-known pharmacodynamic parameter and may have clinical importance for dosing regimens, the mechanism of the phenomenon remains unclear. It has been reported that PAE can also affect bacteria in other ways, through changes in growth kinetics [15], morphology [16], inhibition of enzyme and toxin production [17], loss of adhesive properties [18-20], and susceptibility to host humoral and cellular immunity [21].

It is well known that chlorhexidine has antimicrobial effects against a broad spectrum of oral pathogens [22-27]; however, it has a number of reported side effects, including altered taste, increased calculus formation, staining of teeth and mucous membranes, and, rarely, oral mucosa desquamation and parotid swelling [28-30]. The most obvious and important local side effects are the browning of teeth, restorative materials, and dorsum of the tongue [28,31] and supragingival calculus formation [24,32,33]. If the PAE, PASME, and SME of chlorhexidine occur in vivo, we anticipate that they will make chlorhexidine treatment pharmacodynamically advantageous. Eventually we may reduce the concentration and dosing interval of chlorhexidine, thereby reducing the side effects of this antimicrobial agent.

In conclusion, the present study revealed the PAE, PASME, and SME of chlorhexidine against $S$. mutans, S. gordonii, and L. acidophillus. Chlorhexidine induces a significant PAE and PA-SME in vitro, which may imply a longer effective period during treatment of the oral cavity. Further studies are needed to clarify the in vivo and clinical significance of the PAE and PA-SME of chlorhexidine for oral bacteria prophylaxis.

\section{CONFLICTS OF INTEREST}

The authors declare that they have no competing interests.

\section{ORCID}

\author{
Min Seok Yoo \\ https://orcid.org/0000-0001-7264-8306 \\ Si Young Lee \\ https://orcid.org/0000-0001-8826-1413
}

\section{REFERENCES}

1. Zhanel GG, Hoban DJ, Harding GK. The postantibiotic effect: a review of in vitro and in vivo data. DICP 1991;25:153-163. doi: 10.1177/106002809102500210.

2. Vogelman BS, Craig WA. Postantibiotic effects. J Antimicrob Chemother 1985;15 Suppl A:37-46. doi: 10.1093/ jac/15.suppl_a.37.

3. Craig WA, Gudmundsson S. Poastantibiltic effect. In: Lorian $\mathrm{V}$, editor. Antibiotics in laboratory medicine. Baltimore: Williams \& Wilkins; 1996. p. 296-329.

4. Vogelman B, Gudmundsson S, Turnidge J, Leggett J, Craig WA. In vivo postantibiotic effect in a thigh infection in neutropenic mice. J Infect Dis 1988;157:287-298. doi: 10.1093/infdis/157.2.287

5. Odenholt-Tornqvist I, Löwdin E, Cars O. Postantibiotic effects and postantibiotic sub-MIC effects of roxithromycin, clarithromycin, and azithromycin on respiratory tract pathogens. Antimicrob Agents Chemother 1995;39:221226. doi: 10.1128/aac.39.1.221.

6. Odenholt-Tornqvist I, Löwdin E, Cars O. Postantibiotic sub-MIC effects of vancomycin, roxithromycin, sparfloxacin, and amikacin. Antimicrob Agents Chemother 1992;36:1852-1858. doi: 10.1128/aac.36.9.1852.

7. McDonnell G, Russell AD. Antiseptics and disinfectants: activity, action, and resistance. Clin Microbiol Rev 1999;12:147-179. doi: 10.1128/CMR.12.1.147. 
8. Hiom SJ, Furr JR, Russell AD, Dickinson JR. Effects of chlorhexidine diacetate on Candida albicans, C. glabrata and Saccharomyces cerevisiae. J Appl Bacteriol 1992;72:335-340. doi: 10.1111/j.1365-2672.1992. tb01844.x.

9. Hugo WB, Longworth AR. Some aspects of the mode of action of chlorhexidine. J Pharm Pharmacol 1964;16:655662. doi: 10.1111/j.2042-7158.1964.tb07384.x.

10. Scheie AA. The role of antimicrobials. In: Fejerskov O, Kidd EAM, editors. Dental caries: the disease and its clinical management. Oxford: Blackwell; 2003. p. 179-188.

11. Zhanel GG, Karlowsky JA, Davidson RJ, Hoban DJ. Effect of pooled human cerebrospinal fluid on the postantibiotic effects of cefotaxime, ciprofloxacin, and gentamicin against Escherichia coli. Antimicrob Agents Chemother 1992;36:1136-1139. doi: 10.1128/aac.36.5.1136.

12. Craig WA, Ebert SC. Killing and regrowth of bacteria in vitro: a review. Scand J Infect Dis Suppl 1990;74:63-70.

13. Lee SY. Postantibiotic effects and postantibiotic subMIC effects of amoxicillin on Streptococcus gordonii and Streptococcus sanguis. J Chemother 2000;12:379-384. doi: 10.1179/joc.2000.12.5.379.

14. Li RC, Lee SW, Kong CH. Correlation between bactericidal activity and postantibiotic effect for five antibiotics with different mechanisms of action. J Antimicrob Chemother 1997;40:39-45. doi: 10.1093/jac/40.1.39.

15. Gerber AU, Craig WA. Growth kinetics of respiratory pathogens after short exposures to ampicillin and erythromycin in vitro. J Antimicrob Chemother 1981;8 Suppl C:81-91. doi: 10.1093/jac/8.suppl_c.81.

16. Baker PJ, Busby WF, Wilson ME. Subinhibitory concentrations of cefpodoxime alter membrane protein expression of Actinobacillus actinomycetemcomitans and enhance its susceptibility to killing by neutrophils. Antimicrob Agents Chemother 1995;39:406-412. doi: 10.1128/aac.39.2.406.

17. Shibl AM, Gemmell CG. Effect of four antibiotics on haemolysin production and adherence to human uroepithelial cells by Escherichia coli. J Med Microbiol 1983;16:341349. doi: 10.1099/00222615-16-3-341.

18. Proctor RA, Olbrantz PJ, Mosher DF. Subinhibitory concentrations of antibiotics alter fibronectin binding to Staphylococcus aureus. Antimicrob Agents Chemother 1983;24:823-826. doi: 10.1128/aac.24.5.823.

19. Schifferli DM, Beachey EH. Bacterial adhesion: modulation by antibiotics which perturb protein synthesis. Antimicrob Agents Chemother 1988;32:1603-1608. doi: 10.1128/ aac.32.11.1603.

20. Tylewska S, Hjertén S, Wadström T. Effect of subinhibitory concentrations of antibiotics on the adhesion of Streptococcus pyogenes to pharyngeal epithelial cells. Antimicrob Agents Chemother 1981;20:563-566. doi: 10.1128/ aac.20.5.563.

21. Chopra I, Linton A. The antibacterial effects of low con- centrations of antibiotics. Adv Microb Physiol 1986;28:211259. doi: 10.1016/s0065-2911(08)60240-4.

22. Addy M, Langeroudi M. Comparison of the immediate effects on the sub-gingival microflora of acrylic strips containing 40\% chlorhexidine, metronidazole or tetracycline. J Clin Periodontol 1984;11:379-386. doi: 10.1111/j.1600051x.1984.tb01336.x.

23. Heling I, Sommer M, Steinberg D, Friedman M, Sela MN. Microbiological evaluation of the efficacy of chlorhexidine in a sustained-release device for dentine sterilization. Int Endod J 1992;25:15-19. doi: 10.1111/j.1365-2591.1992. tb00943.x.

24. Löe H, Schiött CR, Karring G, Karring T. Two years oral use of chlorhexidine in man. I. General design and clinical effects. J Periodontal Res 1976;11:135-144. doi: 10.1111/ j.1600-0765.1976.tb00061.x.

25. Lang NP, Ramseier-Grossmann K. Optimal dosage of chlorhexidine digluconate in chemical plaque control when applied by the oral irrigator. J Clin Periodontol 1981;8:189202. doi: 10.1111/j.1600-051x.1981.tb02030.x.

26. Schiïott CR, Löe H, Briner WW. Two year oral use of chlorhexidine in man IV. Effect on various medical parameters. J Periodontal Res 1976;11:158-164. doi: 10.1111/ j.1600-0765.1976.tb00064.x.

27. Steinberg D, Amit U, Brayer L, Sela MN, Friedman M. The effect of sustained-release varnish of chlorhexidine in dental plastic shells on salivary Streptococcus mutans. Clin Prev Dent 1991;13:9-12.

28. Flotra L. Different modes of chlorhexidine application and related local side effects. J Periodontal Res Suppl 1973;12:41-44. doi: 10.1111/j.1600-0765.1973.tb02162.x.

29. Guimaraes AR, Peres MA, Vieira Rde S, Ferreira RM, RamosJorge ML, Apolinario S, Debom A. Self-perception of side effects by adolescents in a chlorhexidine-fluoride-based preventive oral health program. J Appl Oral Sci 2006;14:291296. doi: 10.1590/s1678-77572006000400015.

30. Löe H, Schiott CR. The effect of mouthrinses and topical application of chlorhexidine on the development of dental plaque and gingivitis in man. J Periodontal Res 1970;5:7983. doi: 10.1111/j.1600-0765.1970.tb00696.x.

31. Addy M, Moran J. The formation of stain on acrylic surfaces by the interaction of cationic antiseptic mouthwashes and tea. J Biomed Mater Res 1984;18:631-641. doi: 10.1002/ jbm.820180605.

32. Cancro LP, Paulovich DB, Klein K, Picozzi A. Effects of a chlorhexidine gluconate mouthrinse on dental plaque and calculus. J Periodontol 1972;43:687-691. doi: 10.1902/ jop.1972.43.11.687.

33. Löe H, Mandell M, Derry A, Schött CR. The effect of mouthrinses and topical application of chlorhexidine on calculus formation in man. J Periodontal Res 1971;6:312314. doi: 10.1111/j.1600-0765.1971.tb00623.x. 